\title{
Lactobacillus Counts: A tool for predicting oral cancer in buccal cavity of Hamster rats
}

Sithrangaboopathy N, ThiruneelakandanG, KathiresanK.

Centre of Advanced Study in Marine Biology, Annamalai University, Parangipettai: 608 502, India.

\begin{abstract}
Objectives: The association of microorganisms with oral cancer is yet to be adequately examined. The objective of this study was to assess the lactobacillus counts in saliva in relation to tumour induced by DMBA on buccal pouch of the Hamster rats.

Methods: The Hamster rats were painted thrice a week with DMBA in their right buccal pouch, and also administrated orally with lignin at $4 \mathrm{mg} \mathrm{kg}^{-1}$ and $4 \mathrm{ug} \mathrm{kg}^{-1}$, on alternate days of the DMBA treatment. Appropriate control animals were maintained. After 14 weeks of treatment, lactobacilli counts in saliva from buccal pouch were enumerated and tumour volume in the animals was determined.

Results: The counts of lactobacilli decreased with increasing volumes of tumours.

Conclusion: The Hamster rats with lactobacilli counts of $<6 \times 10^{5} \mathrm{cfu} \mathrm{ml}^{-1}$ in saliva indicates the incidence of oral cancer, thus the lactobacilli counts in the saliva can be used as a tool for predicting oral cancer.
\end{abstract}

Key words: Lactobacillus, oral cancer, Ceriopsdecandra, lignin, DMBA

\section{INTRODUCTION}

Bacteria are known to associate with cancer tissues. Nagy et al.,' have demonstrated a difference in the micro-flora associated with the surface of tumors in comparison to control sites. Patients with oral cancer tend to possess significantly low concentration of beneficial bacteria in their saliva. This is of particular interest because of its potential application as a diagnostic tool to predict oral cancer ${ }^{2}$. Among bacteria, lactobacilli are thought to have beneficial effects in the maintenance of the health condition in humans by preventing colonization and subsequent proliferation of pathogenic bacteria ${ }^{3,4,5}$. These bacteria have been reported to have cancer protective effects in vitro and in vivo ${ }^{6,7,3}$.

The hamster buccal pouch (HBP) carcinogenesis model is the best known animal system for investigating the efficacy of chemo-preventive agents on oral carcinogenesis. HBP carcinomas induced by the application of 7,12- dimethylbenz[a]anthracene (DMBA) to the cheek pouch of Syrian hamsters are morphologically and histologically similar to human oral squamous cell carcinomas.

Correspondence: Prof. K. Kathiresan,

Centre of Advanced Study in Marine Biology,

Annamalai University, Parangipettai. 608502.

E-mail:kathirsum@rediffmail.com

Phone: 04144- 243223,

Fax: $04144-243555$.
In addition, hamster tumours express many biochemical and molecular markers that are expressed in human oral cancer" and hence the HBP model is extensively used. ${ }^{1+1}$ The present study was to determine the lactobacillus counts in the buccal cavity of male hamster and to compare them with tumour incidence.

\section{MATERIALS AND METHODS}

\section{Animals}

Test animals used in this study were male Syrian Hamster rats, aged 8-10 weeks with an average weight of $85 \pm 2 \mathrm{~g}$, obtained from the National Institute of Nutrition, Hyderabad, India. The animals were housed six in a polypropylene cage and provided with food and water and libitum. They were maintained under controlled conditions of temperature $\left(23 \pm 2^{\circ} \mathrm{C}\right)$ with an alternating $12-\mathrm{h}$ light/dark cycle. All animals were fed standard pellet diet (Mysore Snack Feed Ltd., Mysore, India).

\section{Chemicals}

Dimethylbenz[a] anthracene (DMBA) was purchased from Sigma Chemical Company, USA. All other reagents used were of analytical grade.

Preparation of Extracts

Fresh leaves of Ceriopsdecandra (Griff.) Ding Hou were collected from Pichavaram mangrove forest $\left(11^{\circ}\right.$ $\left.27^{\prime} \mathrm{N} ; 79^{\circ} 47^{\prime} \mathrm{E}\right)$ situated in south east coast of India. 
The collected leaves were washed thoroughly in tap water, dried under shade, and powdered.The powdered leaf material (200 g) was extracted twice for $3 \mathrm{~h}$ at room temperature $\left(28 \pm 2^{\circ} \mathrm{C}\right)$ in $600 \mathrm{ml}$ of $70 \%$ ethanol. The residue was extracted twice for $3 \mathrm{~h}$ at $90^{\circ} \mathrm{C}$ with $600 \mathrm{ml}$ of water and centrifuged at $10,000 \mathrm{~g}$ for 10 min. To the supernatant, 6 volume of ethanol was added to precipitate. The residue was extracted twice for $3 \mathrm{~h}$ with $1 \% \mathrm{NaOH}$, and centrifuged to obtain the supernatant. The $\mathrm{pH}$ of supernatant was adjusted to 5.0 with acetic acid. After centrifugation, the precipitate obtained was dialyzed against distilled water and lyophilized. The recovery of the fraction was $0.72 \%$. Based on the IR/NMR pattern, the fraction was identified to belong to the family of coumaryl lignin $^{11}$.

\section{Experimental Design}

The animals were randomized into experimental and control groups divided into six groups. The group-I animals were untreated control painted with liquid paraffin alone on the right buccal pouches using a number- 4 brush three times a week. Group-II animals were painted with a $0.5 \%$ solution of DMBA in liquid paraffin, thrice a week. The group-III animals were painted with DMBA as in the group II, and were also administered orally with lignin extract at a high dose of $4 \mathrm{mgkg}^{-1}$ body weight on days alternate to the DMBA application. Animals in group-IV received only lignin as in Group III. The group-V animals were painted with DMBA as in group II and were also administrated with low dose of lignin $\left(0.1 \mathrm{~g} . \mathrm{kg}^{-1}\right.$ body weight) as in Group-III. The Group VI received the lignin alone at low concentration $\left(0.1 \mathrm{~g} \cdot \mathrm{kg}^{-1}\right)$. The experiments were terminated at the end of $14^{\mathrm{th}}$ weeks. The animals were sacrificed after 14 weeks of the experiment and the tumours were dissected out and measured for volume by using water replacement method.

\section{Isolation of Lactic acid Bacteria from Saliva}

After 14 weeks of experiment, just before the sacrifice of the animal, saliva samples were collected from the right buccal region of the Hamster rats using a swab with the help of Whatman No.1. filter paper (with a diameter of $5 \mathrm{~mm}$ ). The saliva was diluted and plated on de Man Rogosa Sharpe agar (MRS) medium and incubated for $36 \mathrm{~h}$ at room temperature at $37^{\circ} \mathrm{C}$. The colonies formed on the plates were enumerated and is expressed as colony forming units (cfu) per $\mathrm{ml}$.

Morphological and physiological characterization of lactobacilli

Cellular morphology of lactobacilli was observed using a phase-contrast microscope after mounting on a $2 \%$ water agar film. The cultures were analyzed for catalase, $\mathrm{H}_{2} \mathrm{~S}$ production, starch hydrolysis, and sugar fermentation ${ }^{12}$.

In vitro anti-lactobacilli assay for DMBA using disc diffusion method

In order to test the anti-lactobacilli activity of DMBA, the lactobacilli culture was inoculated on sterile MRS medium using a swab and incubated at $37^{\circ} \mathrm{C}$. After 2 $h$, sterile paper discs (5 mm dia.) aseptically impregnated with $5 \mathrm{mg}$ of DMBA per $\mathrm{ml}$ liquid paraffin along with control discs were placed in the Petri plate. After incubating $24 \mathrm{~h}$, the plates were observed for inhibition zone around the discs if any.

\section{Statistical analysis}

One-way analysis of variance and Duncan multiple range tests were used to compare mean values at 0.05 probabilities.

\section{RESULTS}

The microbes isolated from saliva of Hamsters were confirmed to be lactobacilli, based on their morphological and physiological characteristics. The strains are rod shaped, Gram positive, homofermentative, forming white creamy colonies, capable of utilizing sugars (galactose, D-glucose, maltose, sucrose, lactose) and positive to starch hydrolysis and $\mathrm{H}_{2} \mathrm{~S}$ production but negative to catalase.

The results of animal experiment are given in Table 1 and Figure 1.There was no incidence of tumour in the animals untreated and/or treated with lignin alone. These animals exhibited high counts of lactobacilliin a range between $4,500-5,800 \times 10^{2} \mathrm{cfuml}^{-1}$. The DMBAtreated animals and those with lignin at high and/or low doses showed tumour volume of 2.41, 3.84 and $1.50 \mathrm{ml}$ respectively. Thus the highest tumour incidence was seen with DMBA + high dose of lignin treatment and the lowest tumourogenesis with DMBA + low dose of lignin treatment, and the intermediary tumourogenesis were found with DMBA. These animals displayed the bacterial counts of 260, 25 and $100 \mathrm{cfuml}^{-1}$. The lowest bacterial count was detected with the highest tumour incidence in the animals treated with DMBA + high dose of lignin treatment.

\section{DISCUSSION}

Several authors reported that the anti oxidative properties of lignin ${ }^{11}$ and that lactobacillus reduces the incidence of various cancers ${ }^{1,13,14}$. However, it is not documented for oral cancer. In our study, there was 2.6-fold higher tumour volume coinciding with 4 -fold lower bacterial counts in the animals treated with DMBA + high dose of lignin treatment than those with 
Table 1 Counts of Lactobacilli in tumour induced hamsters

\begin{tabular}{lcc}
\hline Treatment & $\begin{array}{c}\text { Counts of Lactobacillus } \\
\left(\mathrm{x} 10^{2} \text { cfu ml }\right.\end{array}$ & Tumour volume (ml) \\
\hline Control & $4,500 \pm 118^{\mathrm{a}}$ & $0.00^{\mathrm{a}}$ \\
DMBA & $260 \pm 103^{\mathrm{b}}$ & $2.41 \pm 0.2^{\mathrm{c}}$ \\
DMBA + lignin $(4 \mathrm{mg} / \mathrm{kg}$ animal $)$ & $25 \pm 14^{\mathrm{b}}$ & $3.84 \pm 0.3^{\mathrm{D}}$ \\
Lignin $(4 \mathrm{mg} / \mathrm{kg})$ & $5,500 \pm 173^{\mathrm{a}}$ & $0.00^{\mathrm{a}}$ \\
DMBA + lignin $\left(0.1 \mathrm{~g} \cdot \mathrm{kg}^{-\mathrm{l}}\right)$ & $1,00 \pm 15^{\mathrm{b}}$ & $1.5^{\mathrm{a}}$ \\
Lignin $\left(0.1 \mathrm{~g} \cdot \mathrm{kg}^{-1}\right)$ & $5,800 \pm 164^{\mathrm{a}}$ & $0.00^{\mathrm{a}}$ \\
\hline
\end{tabular}

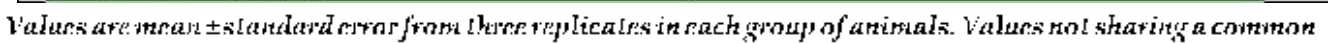

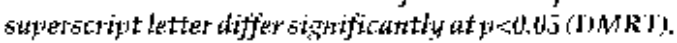

Figure 1 Relationship between counts of Lactobacilli (cfu ml-1) and tumour volume (ml)

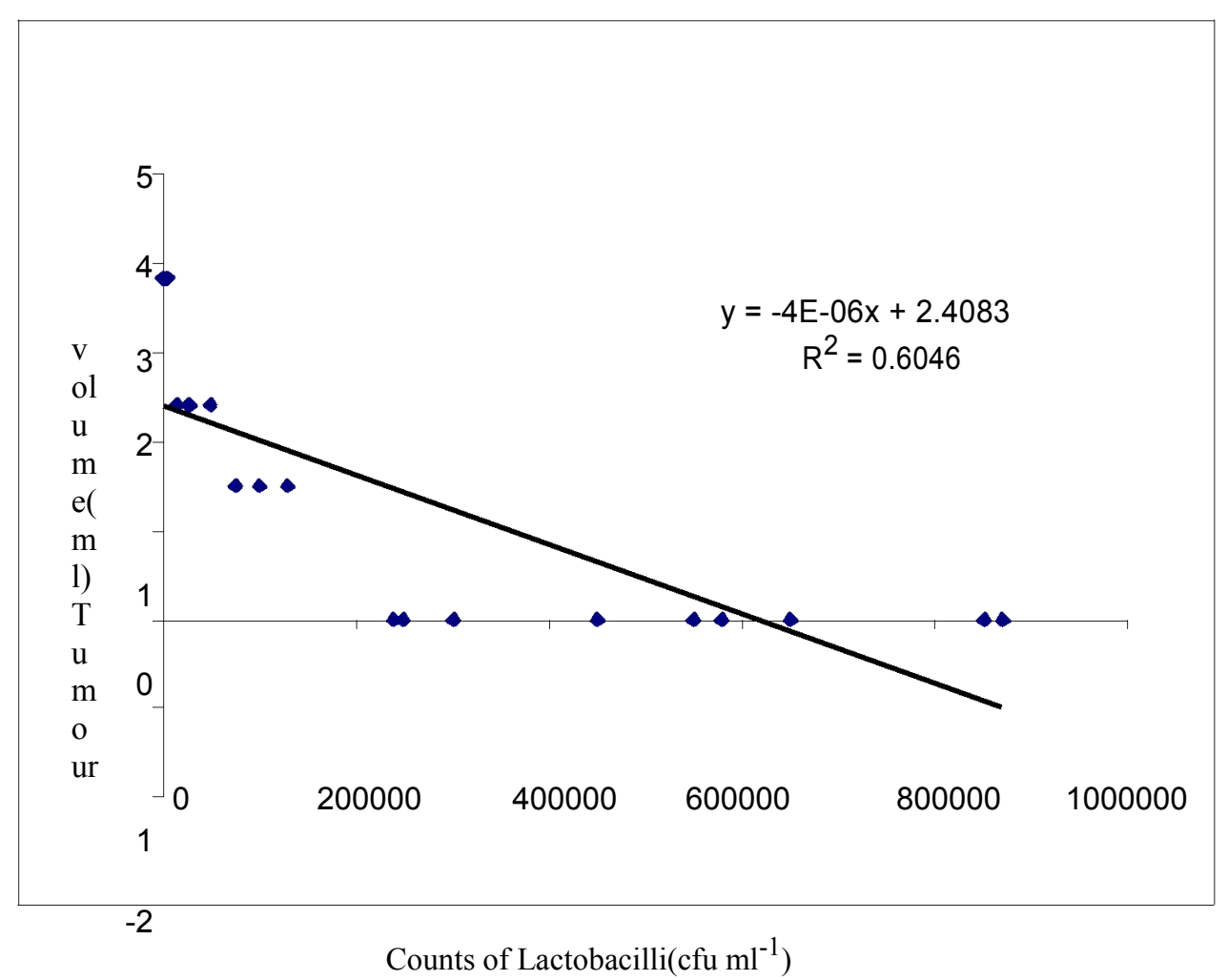


DMBA + low dose of lignin treatment (Table 1). It reveals that the low dose of lignin counteracts the tumourogenesis induced by DMBA, whereas high dose of lignin induces the DMBA-induced tumourogenesis. Further study is required to elucidate mechanism of the different effects. The lignin at high concentration acts as pro-oxidant". It may increase radical intensity produced by DMBA that likely results in tumour formation. However, at lower concentrations, lignin acts as an antioxidant ${ }^{11}$. It may reduce the radical intensity produced by DMBA, consequently reducing the tumour formation.

The present work reveals that the counts of lactobacilli in the buccal cavity can be an indicator of healthy condition of the animals. For instance, the animal with less than $6 \times 10^{5} \mathrm{cfuml}^{-1}$ exhibited the incidence of tumour(Fig. 1). It is important to analyze whether the bacterial count reduction is the cause or consequence of tumourogenesis and whether the reduction in the beneficial bacterial counts makes the animal susceptible to tumourogenesis or it is an aftereffect of the tumourogenic process. Lactobacillus acidophilus strains are known to have anti-mutagenic activity. Binding of mutagens or promutagens to the microbial cells has been suggested to be a possible mechanism of antimutagenicity ${ }^{15}$. Thus the lactobacillus in the present study might have prevented the mutagenic effect of DMBA and hence reduced the tumour formation. However, the DMBA does not have direct anti-bacterial activity on lactobacilli, as observed in vitro anti-lactobacilli assay conducted in the present study. Therefore, the bacterial reduction is likely to be the consequence of tumourogenesis. Beneficial effect of lactobacillus can be attributed to the control of pathogenic microbes that cause various diseases, through the production of antibacterial protein namely bacteriocin by the lactobacilli $i^{12}$ and anticancer substances. The dietary supplements of lactobacilli reportedly decreased the induction of experimental colon cancer in rats ${ }^{3}$.

\section{CONCLUSION}

Based on the observations, lactobacilli in saliva of the buccal pouch in Hamster rats can be used as an indicator of cancer incidence in the animals.

\section{ACKNOWLEDGEMENTS}

The authors are thankful to the authorities of Annamalai University for their help.

\section{REFERENCES}

1. Nagy KN, Sondoki I, Szoke I, Nagy E, and Newman HN. The microflora associated with human oral carcinomas. Oral Oncol 1998; 34:304-308.

2. Mager DL, Haffajee AD, Devlin PM, Norris CM, Posner MR, Goodson JM.The salivary microbiota as a diagnostic indicator of oral cancer: adescriptive, non-randomized study of cancer-free and oral squamous cell carcinoma subjects. J. Transl. Med 2005; 3:27.

3. Goldin BR, Gorbach SL. Probiotics for humans. In: Fuller R. (eds). probiotics. Pp 355376. London: Champman and Hall, 1992.

4. Naidu AS, Bidlack WR, Clemens RA. Probiotic spectra of lactic acid bacteria. CritRev Food SciTechnol 1999; 38: 13-126.

5. Anukam KC, Osazuwa EO, Ahonkhal I, Reid G. 16S rRNA gene sequence and phylogenetic tree of lactobacillus species from the vagina of healthy Nigerian women. Afrij of Biotechnol 2005; 4: 1222-1227.

6. Singh J, Rivenson A, Tomita M, Ishibashi N, Reddy BS. Bifidobacteriumlongum, a lactic acid-producing intestinal bacterium inhibits colon cancer and modulates the intermediate biomarkers of colon carcinogenesis. Carcinogenesis 1997; 18: 833-841.

7. Mcintosh GH, Royle PJ, Playne MJ. A probiotic strain of L. acidophilus reduces $\mathrm{DMH}$ - induced large intestinal tumors in male Sprague-dawley rats. Nut. Cancer 1999; 35: 153-159.

8. Wollowski I, Rechkemmer G, Pool-Zobel BL. Protective role of probiotics and prebiotics in colon cancer.Amer Jof ClinNut 2001; 73:451455.

9 Shklar G. Development of experimental oral carcinogenesis and its impact on current oral cancer research. J Dent Res 1999; 78:1768-1772.

10 Subapriya R, Bhuvaneswari V, Ramesh V, Nagini S. Ethanolicleafextract of neem (Azadirachtaindica) inhibits buccal pouch carcinogenesis in hamsters. Cell BiochemFunct 2004; 22:1- 10.

11 Sakagami H, Kashimita M, Toguchi M, Satoh K, Odanaka Y, Ida Y, Premanathan M, Arakaki R, Kathiresan K, Nakashima $\mathrm{H}$, Komatsu N, Fujimarki M, Yoshihara M. Radical modulation activity of lignins from a mangrove plant Ceriopsdecandra. In Vivo 1998.12:327-332.

12 Vassu T, Smarandache D, Stoica L, Sasarman E, Fologea D, Musat F, Csutak O, Nohit M, Lftime $\mathrm{O}$, Gherasim R. Biochemical and genetic characterization of Lactobacillus plantarumcmgb-1 strain used as probiotic 
